\title{
Bringing the Everyday Life into Engineering Education
}

\author{
$\underline{\text { doi:10.3991/ijac.v4i1.1519 }}$ \\ Gert Pasman, Ingrid Mulder \\ Delft University of Technology, Delft, The Netherlands
}

\begin{abstract}
To successfully design and engineer solutions for today's and tomorrow's rapidly changing and expanding global contexts, in which people are confronted with new opportunities and challenges each day, engineering programs should be training their students to become broad based professionals, who are aware of the actual needs, values and behaviors of the people that use their solutions in their everyday life, work or play. This article argues that in order to built such an awareness, engineering students should acquire direct, first-hand experiences of real people in real contexts. It presents a number of techniques that can be used to gain such experiences. Each technique is briefly described and illustrated with examples from our Industrial Design Engineering program. Knowledge, skills and attitude that are acquired through the use of the techniques are listed and reflected upon. Finally, our experiences with implementing the techniques into our program are discussed in view of their relevance for other engineering programs.
\end{abstract}

Index Terms - industrial design; generative techniques; user centered design; co-creation.

\section{INTRODUCTION}

Traditionally, engineering schools have been concentrated on instructing students in a certain technical discipline, teaching primarily knowledge, skills and attitude specifically relevant for that field. Technical, domainspecific knowledge has been mainly transferred in classroom settings, directly from professor to student, while skills used to manipulate this knowledge have been trained in laboratory exercises and case studies. Both knowledge and skills was then to be directed by the engineering student towards the fulfillment of certain goals, which were influenced by personal values, concerns and preferences, together making up a professional attitude. Several authors, however, have claimed that such traditional instructional methods will not be adequate to prepare students sufficiently for today's rapidly changing and expanding global context, in which people are confronted with more and more social and technological opportunities and challenges, for which appropriate solutions will have to be designed and engineered.

Developments such as the explosion of information resources, the social responsibility of new technologies, the blurring boundaries between disciplines and the ever increasing need for sustainable solutions, all would call for the education of 'The New Engineer' $[1,2,3,5]$ or 'Renaissance Engineers' [4]. Such an engineer should be a broad based professional who is socially and environmentally responsible [1], who understands the context in which he or she will work [2] and can marry technical abilities with a broader understanding of the world [4]. Furthermore, he or she should understand concepts that go beyond their own discipline as well as be capable of communicating their ideas to other disciplines, in order to work in multidisciplinary teams [3]. Finally, they should be peopleoriented [5]. This means that students should able to develop an understanding of how end users will interact with their designs and prototypes, and what their reasons and motivations are for doing so. In this way students become more aware of the needs, values and behaviors of the people that actually use their solutions.

In this article we focus on the latter, arguing that this awareness should be an essential component of the engineer of today and tomorrow and that it therefore should already be initiated during the engineer's training. Since most engineers work in industry they tend not to interact one-on-one with the people who directly should benefit from their services or solutions. In case end users play a role at all in the process, they are often seen as abstract concepts rather than real people. An engineering solution is traditionally considered to be successful if it is effective, efficient or innovative, not if it is usable, desirable or pleasurable. However, in today's complexity, where people are overwhelmed with technology that is more powerful and complex everyday, these latter aspects are becoming increasingly important. Future engineers can not limit themselves to focus on purely technical solutions anymore, they have to broaden their perspective to understand how these solutions will affect the everyday life of the people that they intent to serve.

In this article we describe our experiences of bringing this everyday life of people into a design engineering curriculum. Adapting tools and techniques from ethnographic research, we have been training our students to tap into the deeper needs, values and dreams of potential users, going beyond the traditional focus on product functionalities and characteristics. We explain how these tools and techniques are implemented in our curriculum, show some of their results in courses and projects, and discuss their implications for engineering education in general.

\section{BACKGROUND}

TU Delft's Industrial Design Engineering (IDE) program has been in existence for 40 years. With more than 4000 graduates and more than 300 freshmen every year, IDE has established itself as one of the leading design programs in the world. Its motto is "creating successful product that people love to use", concentrating on designing and improving products which are used daily and intensively, at home or at work. 
The Bachelor's program in Industrial Design Engineering lasts three years, in which design projects provide a thread of continuity throughout the program. These projects provide the opportunity to apply the knowledge and skills that have acquired from various disciplines related to IDE, being engineering, ergonomics, design, marketing and consumer behavior, and sustainability.

After successfully completing the Bachelor's program, students can move on to one of the three two-year Master's programs in IDE:

- Integrated Product Design, intended for those seeking professional mastery at the highest level in the field of product design. The program centers around mass produced consumer products and includes product service systems and products for professional applications.

- Strategic Product Design, which teaches students how to choose a strategic product direction based on insights from the external environment (market analysis, consumer and behavior research, trends and future scenarios, governmental policies, and new technologies and materials) and the wishes and possibilities of the company (product strategy, brand identity, mission/vision, resources).

- Design for Interaction, which teaches students how to design innovative and appropriate products and services by placing the key aspects of human-product interaction, which are use, understanding and experience, in the centre of the design process.

Over the years, new design approaches like "usercentered design" [6,7] and "user experience design" [8] have found their way into all programs. A key aspect of these approaches is that they put the user and not the product at the heart of the process. Initially this primarily meant that users were considered as 'research subjects' which were studied by expert researchers or designers, in order to generate product requirements or to validate design concepts. Typical techniques included interviews, contextual inquiries and observations.

More recently, however, approaches like "participatory design" [9], "co-design" or "co-creation" [10] have promoted a more active engagement of end users by having them participate in design-like activities that are traditionally considered to be the domain of professional designers or engineers. By giving ordinary people (i.e., people with no professional design or engineering background) tools and techniques, such as collages, diagrams or models, they are given the opportunity to articulate their experiences in ways that are more visual and expressive, and consequently, more accessible and understandable. It can be said that increasingly designers are taking on the role of researchers, while users are acting more and more like 'designers'.

This development in both design research and design education has been paralled by a growing need from industry for designers that have the skills to tap deeply into the context in which today's and future products will be used, including the needs, values and motivations of the people that will use them. It is felt that because of the ever increasing complexity of this context a better understanding of it is needed to successfully design products or services that will have to 'live and survive' within this context.

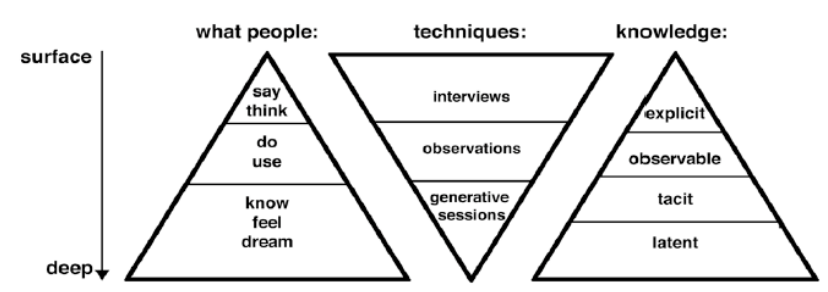

Figure 1. Relations between techniques, knowledge and insights [11] (used with permission.)

Therefore, in several courses and on several occasions throughout the IDE program, students are stimulated to directly interact with end users by visiting the locations where people work, live or play, observing their behaviors, studying their moods and emotions, getting insights in their desires and wishes as well as generating ideas and concepts together etc. In the next paragraph we will discuss some of the techniques that we teach, illustrated with examples from various courses and projects.

\section{TECHNIQUES}

In general, all techniques have their base in ethnography, which is the branch of anthropology that deals with the scientific description of specific human cultures. A core principle of an ethnographic study is that data is collected through direct, first-hand experiences of daily life. In recent years this principle has been adopted in the development of several techniques that should support designers and engineers in acquiring such experiences. In this article we will present and discuss three of those techniques: interviews/contextual inquiry, observations and generative sessions. The scheme in Fig. 1 [11] nicely shows how these three techniques are related to the type of knowledge they produce and the kind of insights that can be gained from them.

\section{A. Interviews/Contextual Inquiry}

Conducting interviews is a classical and often practiced technique to gather information from people. Typically an interview is a conversation between two or more people (the interviewer and the interviewee), where the interviewer asks questions to which the interviewee provides the answers. The style of the interview can vary from strict, where a predefined set of questions is closely followed, to more open, where the questions get adapted to the flow of the conversation. Interviews are particularly suited to acquire explicit knowledge on people's current and past experiences. People are usually good at telling factual things, what they did or are doing now, where they did it, when, etc. However, while this can provide designers and engineers with useful information, it is usually not rich and detailed enough to provide directions for the actual design process.

Therefore, in order to acquire data that is more grounded into the contexts of people's actual life or work, a technique called Contextual Inquiry [12] is often used in design projects. This is also a structured field interviewing technique, however, based on four core principles that differentiate it from the plain, journalistic type of interview:

- Principle of context: Visiting and absorbing the whole context in which the tool, product or system to be designed will be used, is considered essential. 
Thus the interviews should always take place at the location where the new design will be used.

- Principle of partnership: Users are seen as partners in the design process, they are considered to be experts of their personal situations. Interviewing during a contextual inquiry therefore usually does not include fixed, broadly worded questions. Instead, the partnership between the interviewer and interviewee is used to create a dialogue, where the interviewer not only can determine the user's opinions and experiences, but also his intentions and motivations.

- Principle of focus: Throughout the inquiry, the interviewer should constantly be aware of his focus, being a combination of his own assumptions, beliefs and concerns of the particular situation. All that is seen and heard is filtered through this focus and the return of the inquiry therefore heavily depends on 'keeping focused'. Expressing this focus to the interviewee also makes forming a partnership easier.

- Principle of interpretation: After gathering the data, meaning has to be assigned to it through interpretation. Since design and engineering is nowadays commonly done in (multidisciplinary) teams, the goal of the interpretation principle is to build a shared understanding within the team. This is usually done in an open discussion, where the interviewer walks through the results of the inquiry, while the other teams members listen, ask questions and make comments.

In the course Interaction and Electronics, which is running in the second year of the Bachelor program, students are given the assignment to design the user interface of a Personal Shopping Assistant (PSA). This is a small computer device with a touch screen, which is mounted to a shopping cart. All products in the store are marked with an RFID-tag by means of an adhesive label, storing a special number known as the Electronic Product Code. Through this unique code detailed information, such as manufacturer, shipping date, price, weight and best-before date, can be retrieved of each product. The interface of the PSA should thus provide the customers of the store with a number of functions, which should support their shopping process. For example, the device might give suggestions on special offers and show where these products are located in the store.

To gather requirements for their design, the students have to conduct a contextual inquiry, studying real users doing real tasks in real situations. For this students visit stores, conduct short interviews with customers, observe their behavior, map out the layout of the store etc. They are urged to take pictures or shoot videos (if permission is granted) to capture the actual context as rich as possible. Taking into consideration that their subjects are not designers and are therefore not trained to think of new functionalities, they have to look actively for opportunities in their subjects' behaviors, needs, preferences, social activities, daily routines etc.

Consequently, the results of their contextual inquiries need to drive their further design process. This means that emphasis was put on producing rich and inspiring visuals of a highly informative character instead of thick and wordy reports filled with demographics and statistics. Experience has shown that such a format is much better suited to communicate to others, mainly because of its



Figure 2. Infographic showing the results of a contextual inquiry

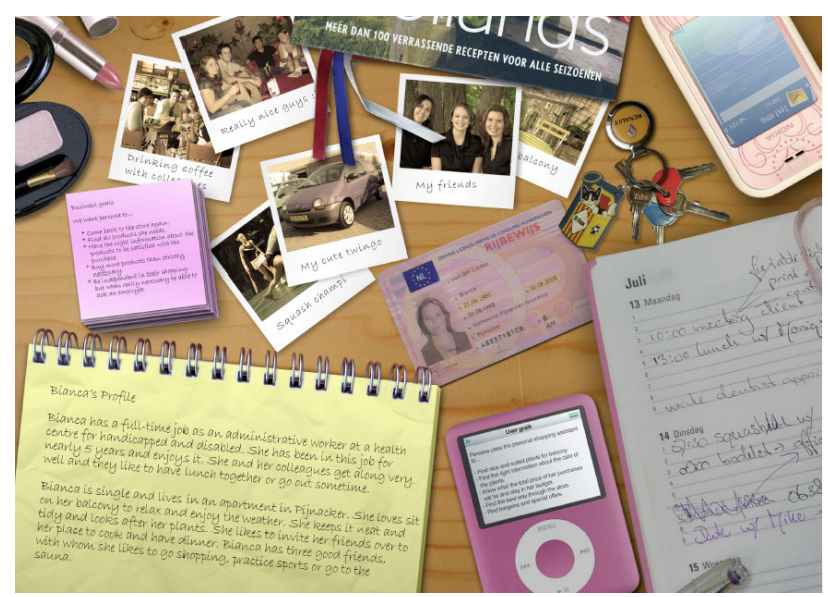

Figure 3. Persona depicting characteristics of a possible future user

compact and attractive qualities. Fig. 2 shows an example of such a presentation format.

Another, popular way of condensing the results is by creating a persona, which is a fictitious character that is created to represent a user type within a targeted demographic that might use the product, system or service to be designed [13]. Personas give a human face to otherwise abstract data about potential users, thus helping to better infer what a real person might need. Creating a believable persona involves coming up with a rich identity and a visually compelling character that gives much relevant information for the actual design stage.

Personas usually include a name, a photograph, a personal profile, interesting quotes, goals and motivators. (Fig.3). Again, by presenting the results of their study in such a way students are forced to stay close to the people they have interviewed, the situations that have encountered, the locations they have visited etc.

\section{B. Observation}

A technique that is often used in combination with or as integral part of a contextual inquiry, but can also be used independently, is observation. Carrying out accurate observations involves much more than just watching people doing things. It requires a sensitivity and alertness for the particular routines, behaviors and interactions people exhibit in certain situations. For this an open mind is as much needed as an open eye, since many of the things people do or how they behave in day-to-day situations, could easily be taken for granted. More than often there 
are conflicts in how people say to behave and how they actually behave, without them being aware of it.

Good observation starts by deciding first what will be observed. Since many contexts are very rich, a clear focus is again essential not to get overwhelmed by all impressions. For this reason students are urged to come up with a plan before the actual observations are conducted. Being at the location, they are told to be as unobtrusive as possible in order to influence the context as less as possible. Camera's can be used to record interesting situations, but permission to use them should always be asked for. Things that can be looked for are certain routines as expressed through repeated activities, body postures or interactions. However, also extreme behavior should be recorded, since sometimes one 'strange' observation can trigger a whole range of possible solutions.

\section{Generative sessions}

While interviews, contextual inquiries and observations all can and will provide designers and engineers with valuable information about what people think, say, do or use, they tend to fall somewhat short when it comes to getting access to the deeper values, whishes and needs of people: what they know, feel and dream. In reaction to this, various method and techniques have therefore more recently emerged that try to address those latter type of information.

Within our IDE research program, substantial work has been done on the development of one of those technique, called contextmapping [14]. Building on the influential work of Sanders [15], contextmapping tries to create an overview of the context surrounding the use of a current or future product by gathering and analyzing personal experiences of real users regarding that particular context. Over last years the technique of contextmapping has been implemented in several IDE-courses [16].

The core of a typical context mapping process is a socalled generative session [11], in which participants first create artifacts such as collages, diagrams or models, and then are asked to present and explain their creations. The premise is that through telling these often personal stories they are able to re-live previous experiences with a certain product, system or context more vividly and deeply. These stories are usually recorded on video and audio, and sometimes transcribed, for later analysis.

Preceding a generative session participants might receive a specially designed sensitizing package or cultural probe [17], which consists of small exercises or activities which are to be completed before the actual session. An often used format for such a probe is a workbook or diary, which contains small tasks for each day. The idea is that by doing these exercises the participants get triggered and motivated to explore the context of product use before the generative session.

After conducting a generative session the results are analyzed, usually by classifying quotes, observations, remarks etc. in meaningful categories. The conclusions are then to be communicated, again not in thick reports, but in ways that will enhance an understanding for and empathy with the users. Possible means for this are collages, card sets or diagrams. For an extensive description of the technique of contextmapping and generative sessions, the interested reader is referred to Sleeswijk Visser et.al.[11].

Exploring Interactions is a course in the Design for Interaction master's program. In this course students are required to formulate their own design project around a certain theme. Broad and abstract themes, such as 'Fear and Fearless', 'Power', or 'Trade', guide the students in their explorations and give them the opportunity to pick a topic they really like. The focus of the course is on analyzing and conceptualizing human-product interactions in relation to the physical, cultural, technological, and social contexts in which new product design(s) will be used. Consequently, getting direct access to these contexts is a substantial part of this course.

Students are encouraged to explore the context for which they intent to design. Observations and interviews are therefore extensively used, but considering the conceptual character of the course, many students also use contextmapping. Fig. 4 shows an example of a workbook, used to sensitize possible participants of a generative session. The topic that is addressed here is shoes. The exercise on left asks people to describe or draw the shoes they are wearing on that particular day, while the exercise on the right is about visualizing one's appearance and the appearance of others.

The workbooks that are filled in by the participants, are subsequently used as input for the actual generative session, in which the topic is much deeper explored. Fig. 5 shows a participant in an actual session, working on a collage that has to be presented and discussed later in the session. Sheets with inspirational images are given, but participants can also bring or create their own images, keywords etc.


Figure 4. Example of a workbook, used to sensitize participants before a generative session. 




Figure 5. Participant creating a collage in a generative session.

\section{KNOWLEDGE, SKILlS AND ATtITUdE}

Problem-based learning and realistic design projects are key in offering a rich and challenging learning environment; such realistic projects should be problem-based and should involve the activation of prior experience, the demonstration and application of skills, and the integration of these skills into real-world activities [18]. Throughout the IDE program, students work on several design projects, in which they apply their knowledge and skills, obtained in different courses, in an integrated manner to solve a real-life problem (similar to those they will encounter in their professional career). The integration of knowledge, skills and attitudes is at the origins of competency-based learning and is therefore increasingly being incorporated into university programs in general [19].

Central in all of the techniques described in the previous section is that they require students to leave the comfort zone of the classroom and take their presumptions, beliefs and ideas out into the real world. Through this they gain access to a different kinds of knowledge, that is based on everyday experiences instead of textbook examples. Furthermore, they get to train and sharpen their research and communication skills. Interestingly, we have noticed that the direct confrontation with real life situations and the interactions with ordinary people stimulates them to reflect on their personal attitude towards people, problems as well as their own role as designers and engineers.

\section{A. Knowledge}

Experiences from various courses and projects have shown that these techniques provide our students the means to tap into a rich and valuable body of experiential knowledge, which they could not have acquired in the classroom, from textbooks or from websites. While in education most situations get abstracted and simplified in order to demonstrate a certain principle or phenomenon, in real life such abstractions hardly exist. By studying the rich contexts of everyday life through direct interactions with the people who live, work or play in them, students are encouraged to put the mostly theoretical knowledge that they have acquired through their formal education into a different perspective.

This can lead to new discoveries and insights. More than once students reported how seemingly simple and ordinary situations turned out to be very rich and complex when researched carefully. They were often surprised to see what people actually do, how they use products in ways totally different from the instructions in the user manual, how they have developed certain routines to interact with other people, products or systems etc.

\section{B. Skills}

The specific nature of the techniques, with their emphasis on direct, first-hand experiences, on active collaboration and on visual, design-directed communication, also comes with a specific set of skills that is desired to successfully apply them.

First, the cooperative nature of the techniques requires students to practice their communication skills with people who have a different mindset, a different jargon and different set of needs and values. Contacting ordinary people, talking with them about their every experiences, listening to their wishes and concerns without prejudices, explaining goals and motives to them in non-technical terms, involving and stimulating them into design-like situations; these all require good 'soft' communication skills that are usually not engineers' greatest forte. With projects becoming more and more multi-disciplinary, such skills have an increasingly valuable quality.

In preparing the material, such as for the workbooks or the generative sessions, research questions or topics should be presented in an attractive way to stimulate participation. Furthermore, communicating the results of the techniques usually involves condensation and translation of the results in ways that should be easily understandable as well as highly informative. Therefore students are stimulated to create infographics, collages, moodboards or storyboards. We have learned that through their abstraction and attractiveness, these means communicate much better than thick, wordy reports. In addition, students' presentation skills are also heavily trained in conducting these techniques.

Finally, by interacting with people with different backgrounds, with different levels of education, coming from different cultures, students also train their social skills. By having to involve and motivate participants or having to facilitate and direct group sessions, students develop a better understanding of and feeling for how to deal with group dynamics, social or economic status and differences in personality. Again, such skills are very valuable for working in today's and tomorrow's complex, global society.

\section{Attitude}

All techniques discussed in this article share the simple premise that first-hand experiences of the context to be designed or engineered for are essential when solving 
problems and creating solutions for this context. This requires from students that they step out of their comfort zones, not just on a physical level by leaving the classroom and going out on the streets, but even more so on a mental level, by leaving the comfortable, well-known environments and mindsets of design or engineering students and entering the everyday life of real people in real contexts.

From our experiences so far we can conclude that this change in perspective enabled our students to establish a much deeper and richer contact with their users, learning about ordinary situations, rituals and problems directly from the source. They have developed a greater awareness of basic human needs, values and limitations, which helps them to better assess the qualities of their own ideas and solutions. Furthermore, using the techniques and learning from their experiences most likely enhances their sensitivity for possible problems or opportunities in their own context.

Finally, from a learning perspective, the informal character that can be found in, for example, generative sessions, in which designer and user work side-by-side might even transform the learning process from a one-way knowledge transfer into an interactive, two-way dialogue in which both engineering student and potential user dynamically learn from each other.

\section{Discussion}

So far we have presented our view that students in engineering disciplines need to develop a better understanding of today's rich and complex contexts and the people who live in them, in order to design and engineer successful solutions, now and in the near future. We have argued that such an understanding can best be acquired through first-hand encounters and we have therefore presented our experiences with a number of techniques to tap into the everyday life of real people in real situations. We have explained each technique and illustrated it with examples. Finally, we have discussed how these techniques have contributed to the competences of our students.

It might be clear that we consider it essential for upcoming designers and engineers to acquire a thorough understanding of the user and the context of use. However, putting this into the curriculum does not automatically lead to applying these additional competences in practice. Learning by doing is crucial for obtaining a good understanding of these techniques. Moreover, not only a proper execution of the techniques need to be learnt, students also need to be able to select the right technique that fits the current research and design goal. This is not trivial. In their first practices students might start quite axiomatically 'we have to do the workbook now' and only after more design experience, their confidence and awareness on how the different techniques can be helpful in design projects increases.

Interestingly, the quality of data collected by teams that deliberately select a certain technique usually is much richer and better suitable for inspiring the design process, whereas teams that just execute some technique might get disappointed, as their data did not show something they did not know beforehand. In fact, starting with an attitude to get evidence for preconceived ideas often does not gain new insights as well. In sum, the techniques we presented here are meant for idea generation, they do not focus on validating results.

Furthermore, we would like to emphasize the value of qualitative data. High numbers do not automatically stress importance of a topic. Many remarks in the same direction might just be an indication of the obvious, while one peculiar quote could trigger a whole new design direction. Thus not only using the right techniques, but also the ability of analyzing and interpreting the data collection is important. Moreover, in order to use these insights to inform the remainder of the design process, the knowledge transfer of user insights and requirements should be carefully guided.

As said before, the learning by doing approach has been taken to emphasize the previously discussed knowledge, skills and attitudes in the curriculum. For this reason, a lot of studio work has been reserved in the curriculum. Although part of a learning-by-doing approach is self-study, it also requires an intense tutoring system to stimulate reflection and discussion, which is time-demanding for our teaching staff. Applying the techniques is also workintensive for the students. Collecting data through observations and interviews, preparing sensitizing packages, conduction generative sessions, analyzing the data; communicating the results: these are activities that require considerable time, effort and dedication. The pay-off, however, is often a very rich set of possible design directions.

One might argue that our program is be much more design-oriented and human-centered than traditional engineering programs, such as mechanical or electrical engineering, and that therefore the presented techniques are much more suited for our students than for 'hard-core' engineering students. Design students would have to have a profound understanding of the everyday needs and wishes of prospective users, since consumer products that are unwanted, unusable or undesirable would simply be rejected by the market.

While this might be true, it is strongly believed that these techniques could be of value to more traditional engineering disciplines as well. After all, even very technical and professional products or systems have end users too. Real people with various backgrounds, that have to service, maintain, monitor or operate increasingly complex machines and devices in increasingly complex contexts and situations. Should these people not have the right to work with products and systems that are usable, pleasurable or even desirable too? And isn't it the obligation of the engineer, most likely in collaboration with other disciplines, to provide them with products and systems that have those qualities?

\section{CONCLUSIONS}

Good engineering today requires more than technical problem solving skills, a profound knowledge of mathematics and dynamics or an excellent understanding of material behavior or software algorithms. It also calls for a deeper understanding of and a greater sensitivity for the day-to-day situations and contexts in which technological solutions and innovations have to assimilate, and of the people who will use them to live, work or play. If so, then why not go out and explore these contexts and situations, observe those people, talk to them, invite them for design sessions or involve them into the development process. 
Although contact with the actual end-user might not be so obvious for all engineering disciplines, due to the increased multidisciplinary character of design projects all kinds of engineers have to communicate across different disciplines, and thus have contact with either internal or external users. The techniques presented and discussed in this article, with some modifications here and there to make them better suited for a specific discipline, could be used as a framework for exploring and investigating the everyday life of these users. Therefore it is our strong belief that these techniques and the knowledge, skills and attitude that they bring with them, could be of considerable value to any engineering program.

\section{REFERENCES}

[1] S. Beder, The New Engineer. Sidney: Macmillan, 1998.

[2] E. Conlon, "The new engineer: between employability and social responsibility", European Journal of Engineering Education, Vol. 33, No.2, pp. 151-159, May 2008 doi:10.1080/03043790801996371

[3] A. Rugarcia, R.M. Felder, J.E. Stice, and D.R. Woods, "The Future of Engineering Education: I. A Vision for a New Century." Chem. Engr. Education, Vol. 34, No. 1, pp. 16-25, 2000.

[4] J. Ogando (2008, March 17), Teaching the new engineering skills [Online]. Available: http://www.designnews.com/article/11425Teaching_The_New_Engineering_Skills.php

[5] J.I. Goldstein. (2004, February). The New Engineer? Available: http://www.casa.umass.edu/uploads/uploads/Files/EngTrends_0 204.pdf

[6] D. Norman, The psychology of everyday things. New York: Doubleday, 1988.

[7] K. Vredenburg, S. Isensee, C. Righi, User-centered design: an integrated approach, Prentice Hall, 2001.

[8] B. Buxton, Sketching User Experiences: Getting the Design Right and the Right Design, Morgan Kaufmann, 2007.

[9] D. Schuler, A. Namioka, Participatory design: Principles and practices. Hillsdale, NJ: Erlbaum, 1993.

[10] E.B.-N. Sanders, P.J. Stappers, "Co-creation and the new landscapes of design", CoDesign, Vol. 4, No. 1, pp. 5-18, Mar. 2008. $\underline{80 / 15710880701875068}$

[11] F. Sleeswijk Visser, P.J. Stappers, R. van der Lugt, E.B.-N. Sanders, "Contextmapping: experiences from practice",
CoDesign, Vol.1, No. 2, pp. 119-149, June 2005. doi:10.1080/15710880500135987

[12] H. Beyer, H., K. Holtzblatt, K. Contextual design: Defining customer-centered systems, Morgan Kaufmann, San Francisco, 1998.

[13] S. Mulder, The User Is Always Right: A Practical Guide to Creating and Using Personas for the Web, New Riders Press, 2006.

[14] http://www.contextmapping.com/. Accessed on 2009, 4 November.

[15] E.B.-N., Sanders, U. Dandavate, "Design for experiencing: New tools" Proc. of the First International Conf. on Design and Emotion, edited by C.J. Overbeeke and P. Hekkert, TU Delft, 1999.

[16] P.J. Stappers, F. Sleeswijk Visser, Bringng participartory techniques to industrial design engineers, in International Conf. on Engineering and Product Design Education, Newcastle upon Tyne, UK, 2007, pp. 117-122.

[17] W. Gaver, T. Dunne, E. Pacenti, "Cultural Probes", ACM Interactions, No. 6, pp. 21-29, 1999. doi:10.1145/291224.291235

[18] M. D. Merill, "First principles of instruction," Educational Technology Research and Development, vol. 50, pp. 43-59, 2002. doi:10.1007/BF02505024

[19] G. A. Bechtel, Davidhizar, R., Bradshaw, M.J., "Problem-based learning in a competency-based world," Nurse Education Today, vol. 19, pp. 182-187, 1999. doi:10.1016/S0260$\underline{6917(99) 80003-3}$

\section{AUTHORS}

Gert Pasman is an Assistant Professor with the Faculty of Industrial Design Engineering, Delft University of Technology, The Netherlands (g.j.pasman@tudelft.nl)

Ingrid Mulder is an Associate Professor with the Faculty of Industrial Design Engineering, Delft University of Technology, The Netherlands and a Research Professor at the School of Communication, Media and Information Technology, Rotterdam University of Applied Technologies, The Netherlands. (i.j.mulder@tudelft.nl)

A version of tis paper was presented in the IEEE EDUCON 2010 conference and selected for submission to this journal. It received a commendation in the Educational Methods and Learning Mechanisms in Engineering Education area of this conference.

Submitted November $20^{\text {th }}, 2010$. Published as resubmitted by the authors January $27^{\text {th }}, 2011$. 